Supporting Information

\title{
Perovskite solar cells based on low-temperature processed indium oxide electron selective layers
}

\author{
Minchao Qin, ${ }^{\mathrm{a}}$ Junjie Ma, ${ }^{\mathrm{a}}$ Weijun Ke, ${ }^{\mathrm{a}}$ Pingli Qin, ${ }^{\mathrm{a}}$ Hongwei Lei, ${ }^{\mathrm{a}}$ Hong Tao, ${ }^{\mathrm{a}}$ Xiaolu Zheng, \\ Liangbin Xiong, ${ }^{a}$ Qin Liu, ${ }^{\mathrm{a}}$ Zhiliang Chen, ${ }^{\mathrm{a}}$ Junzheng Lu, ${ }^{\mathrm{a}}$ Guang Yang ${ }^{\mathrm{a}}$, and Guojia Fang*a
}

${ }^{a}$ Key Lab of Artificial Micro- and Nano-Structures of Ministry of Education of China, School of Physics and Technology, Wuhan University, Wuhan 430072, People's Republic of China

*Corresponding Author. E-mail: gifang@whu.edu.cn 


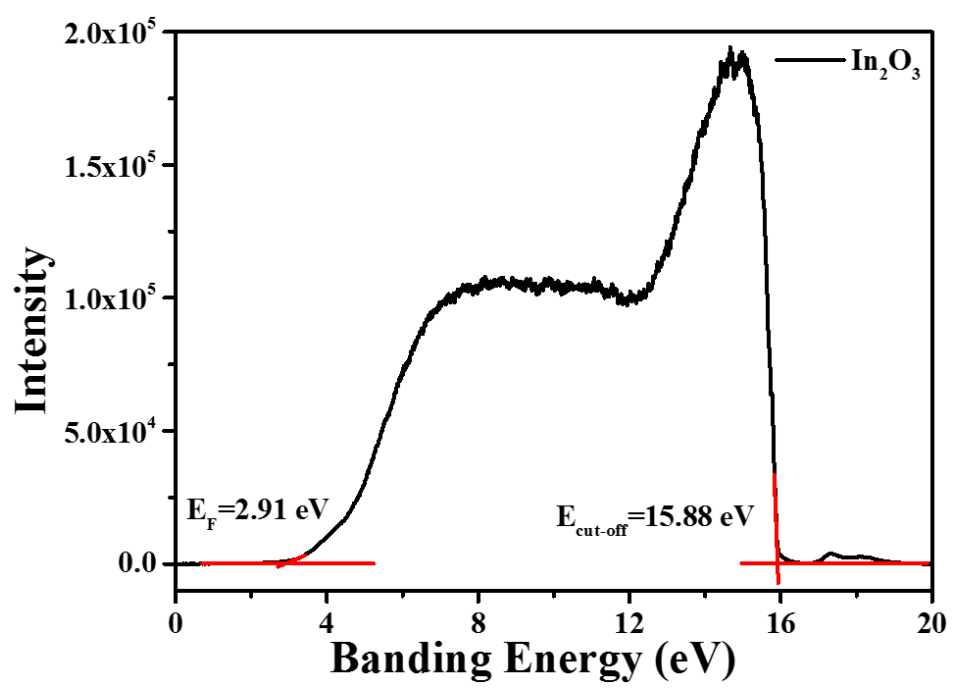

Figure S1. UPS of the $\operatorname{In}_{2} \mathrm{O}_{3}$ layer.

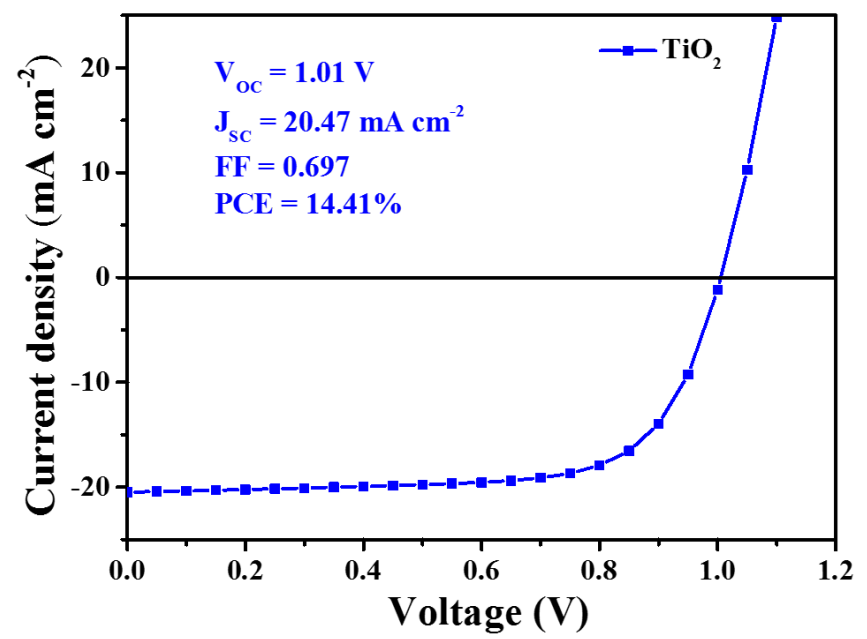

Figure S2. $J-V$ curve of the PSCs based on $\mathrm{TiO}_{2}$ films. 


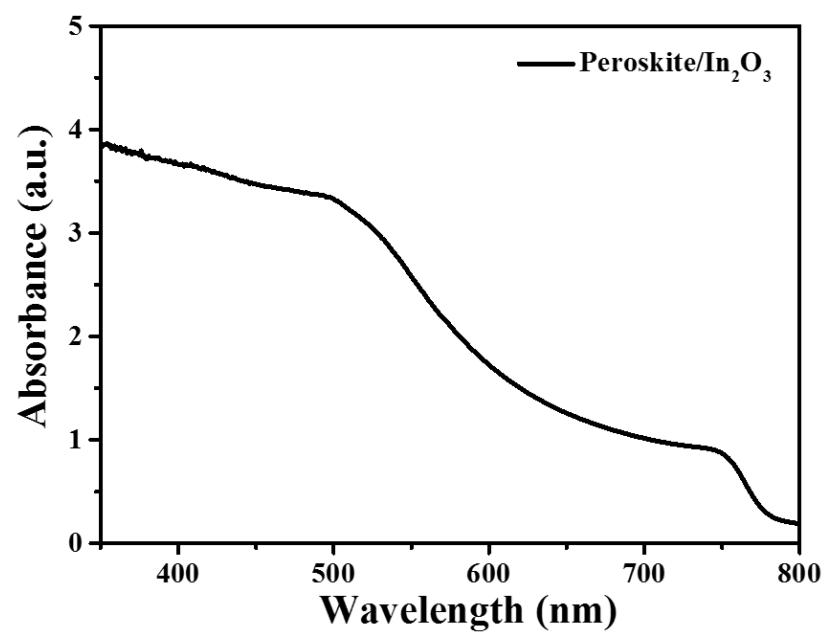

Figure S3. UV-Visible spectra of perovskite layers based on $\operatorname{In}_{2} \mathrm{O}_{3}$ ESL.

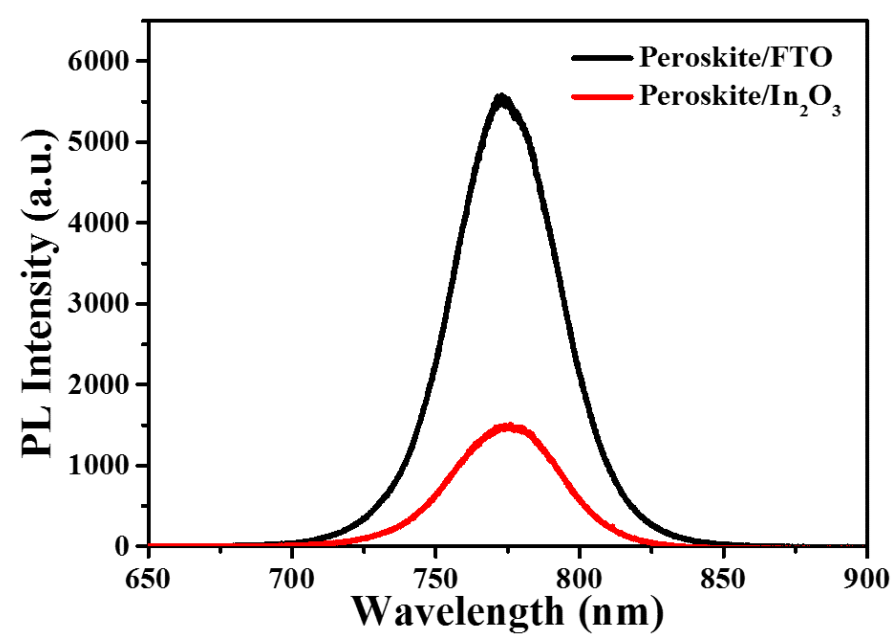

Figure S4. PL spectra of the quenching samples (structure: FTO/perovskite or $\mathrm{FTO} / \mathrm{In}_{2} \mathrm{O}_{3} /$ perovskite). 

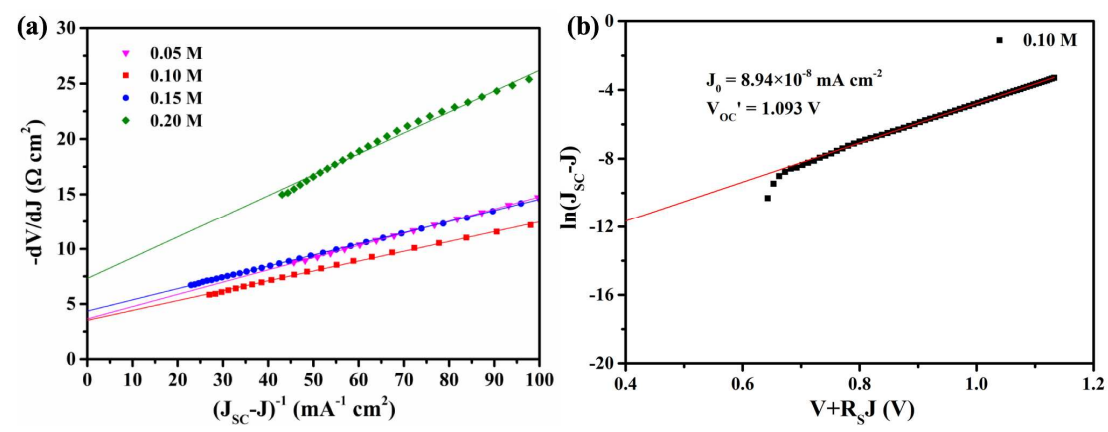

Figure S5. (a) Plots of $-\mathrm{dV} / \mathrm{dJ}$ vs $\left(J_{S C^{-}} \mathrm{J}\right)^{-1}$ with the linear fitting curves on them based on different $\mathrm{In}_{2} \mathrm{O}_{3}$ films (b) and $\ln \left(J_{S C^{-}} \mathrm{J}\right)$ against $\mathrm{V}+R_{S} \mathrm{~J}$ with a linear fitting curve based on $0.10-\operatorname{In}_{2} \mathrm{O}_{3}$ film.

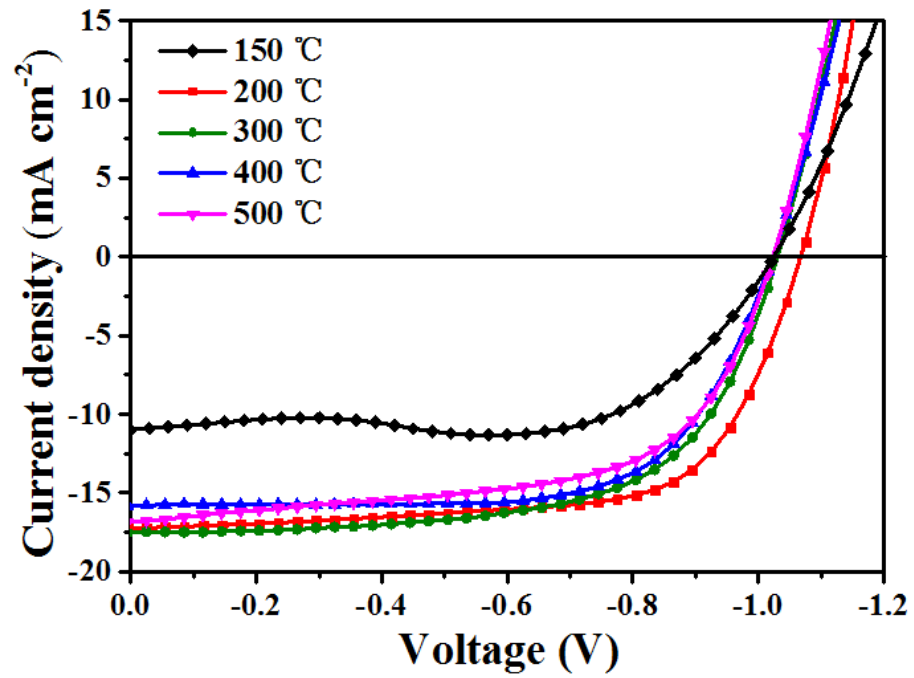

Figure S6. $J-V$ curves of the PSCs based on $\mathrm{In}_{2} \mathrm{O}_{3}$ films with different annealing temperature. 


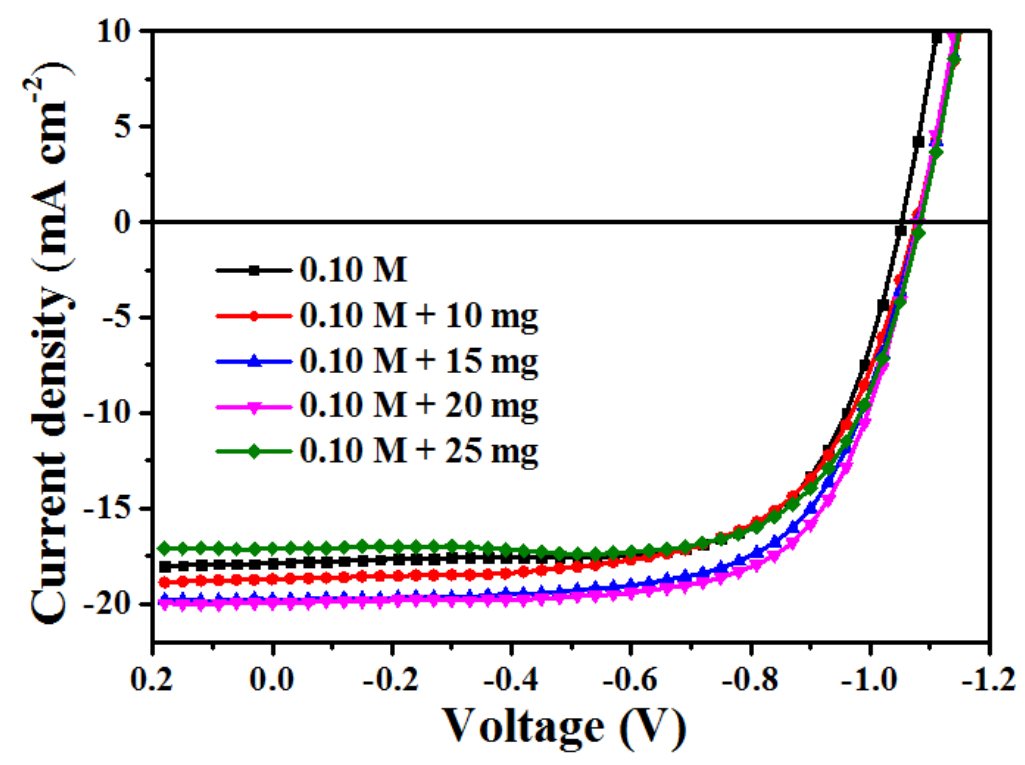

Figure S7. $J-V$ curves of the $\operatorname{In}_{2} \mathrm{O}_{3}$-based PSCs containing PCBM with different thickness.

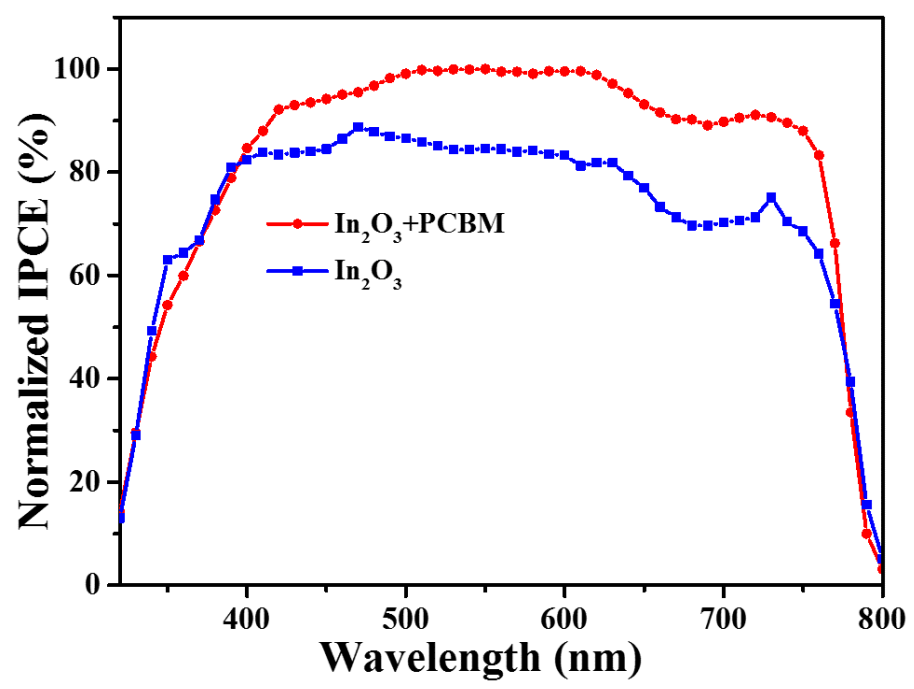

Figure S8. Normalized IPCE spectra of the $\mathrm{In}_{2} \mathrm{O}_{3}$-based PSCs with and without a PCBM layer. 

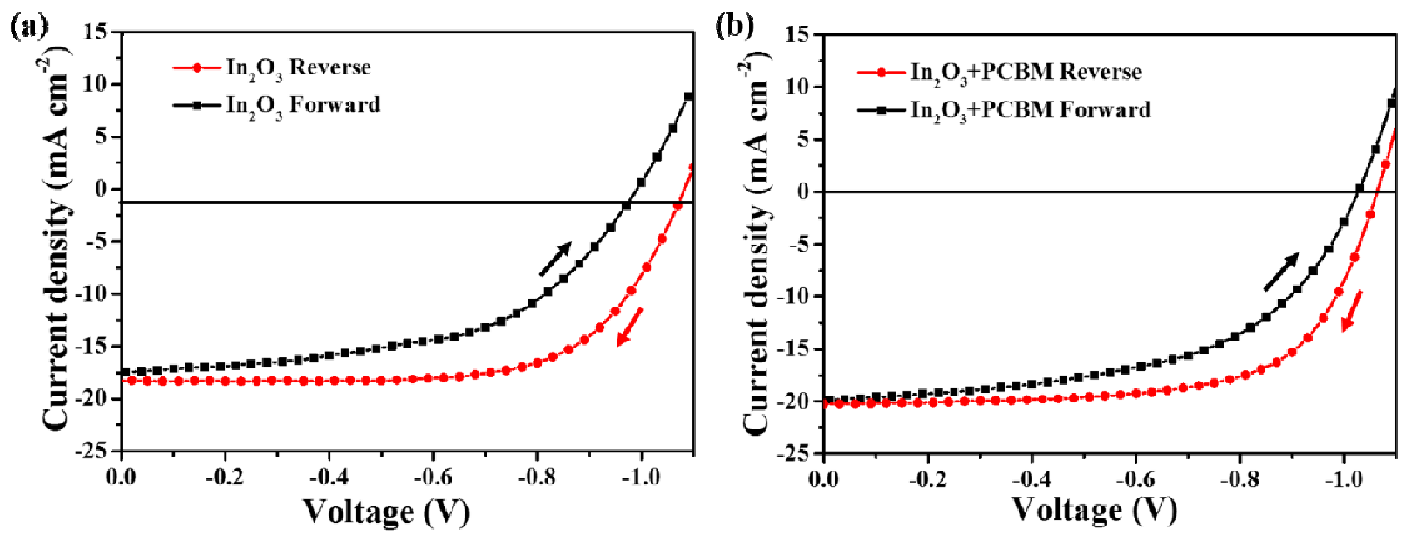

Figure S9. $J$ - $V$ curves of the $\operatorname{In}_{2} \mathrm{O}_{3}$-based PSCs (a) without and (b) with a PCBM layer measured under reverse and forward voltage scanning with AM1.5G illumination.

\section{Table S1}

The two theta, FWHM, and the average crystallite size of $\operatorname{In}_{2} \mathrm{O}_{3}$ after different temperature treatment.

\begin{tabular}{cccc}
\hline Annealing temperature $\left({ }^{\circ} \mathrm{C}\right)$ & $2 \theta\left({ }^{\circ}\right)$ & FWHM $\left({ }^{\circ}\right)$ & Average crystallite size (nm) \\
\hline 200 & 30.662 & 0.694 & 11.74 \\
300 & 30.603 & 0.690 & 11.80 \\
400 & 30.642 & 0.438 & 18.60 \\
500 & & & 20.42 \\
\hline
\end{tabular}

